\title{
HUBUNGAN POLA ASUH ORANG TUA DENGAN KEJADIAN TEMPER TANTRUM PADA USIA TODDLER DI DUKUH PELEM KELURAHAN BATURETNO BANGUNTAPAN BANTUL
}

\author{
Nisaus Zakiyah \\ PKH Dinsos Ponorogo \\ Pascasarjana Ilmu Kesehatan Masyarakat Universitas Sebelas Maret Surakarta Indonesia
}

\begin{abstract}
Age ofl-3 years old is the age which is easily to get temper tantrum. The children are not able yet to express their wants and needs clearly. The effect of temper tantrum could be dangerous for example the child could be rolling on the floor and could hurt himself. The purpose of the study was to investigate the relationship between parents' parenting styles and temper tantrum cases on toddlers in Pelem Baturetno Banguntapan Bantul in 2015. The study employed survey analytic research with cross sectional approach. The samples were 41 respondents taken through total sampling technique. The data were analyzed by using Pearson product moment. Parents' parenting style tends to be poor such as let the child crying, rarely make complement, compare children, shout, and never ask children's opinion. Meanwhile, the temper tantrum frequently happen are whining, crying, and screaming. The significance value of Pearson Product Moment is 0.027 ( $p<0.05)$. It means that there is a relationship between parents' parenting style with temper tantrum on toddlers with correlation value of 0.344 which shows low relation. There is a relationship between parenting style with temper tantrum case on toddler in Pelem Baturetno Banguntapan Bantul in 2015. Parents are expected to give parenting with love, to create normal rules, to be consistent, to give responsibility, to be role models, and to give complement so that those can reduce the temper tantrum.
\end{abstract}

Keywords : parenting style; temper tantrum; toddler.

Abstrak: Pola asuh; Temper tantrum;Toddler. Usia 1-3 tahun adalah usia rawan temper tantrum, anak-anak belum terampil mengungkapkan keinginan dan kebutuhannya dengan jelas. Akibat yang ditimbulkan temper tantrum cukup berbahaya, misalnya anak yang melampiaskan kemarahannya dengan cara bergulingguling dilantai yang keras dapat menyebabkan anak cedera. Penelitian ini dilakukan untuk mengetahui hubungan pola asuh dengan kejadian temper tantrum pada anak usia toddler di Dukuh Pelem, Kelurahan Baturetno, Banguntapan, Bantul Tahun 2015. Metode pada penelitian ini merupakan penelitian survey analitik dengan pendekatan cross sectional. Sampel yang digunakan 41 responden dengan teknik sampling yang digunakan total sampling. Analisis menggunakan Pearson product moment. Hasil penelitian menunjukkan pola asuh orangtua masih cenderung kurang baik, acuh saat anak menangis, kurang memuji, masih membandingkan anak, menegur dengan keras, tidak meminta pendapat anak. Sedangkan kejadian temper tantrum yang sering terjadi adalah merengek, menangis, dan menjerit. Nilai signifikansi Pearson Product Moment sebesar 0,027 ( $\mathrm{p}<0,05)$, sehingga ada hubungan pola asuh orangtua dengan kejadian temper tantrum pada anak usia toddler dengan keeratan hubungan sebesar 0,344 
menunjukkan keeratan rendah. Simpulan pada pnelitian ini ada hubungan pola asuh dengan kejadian temper tantrum pada anak usia toddler di Dukuh Pelem, Kelurahan Baturetno, Banguntapan, Bantul Tahun 2015. Saran Orangtua dapat memberikan pengasuhan dengan kasih sayang, menciptakan aturan yang wajar, konsisten, memberikan tanggung jawab, menjadi model yang baik, memuji anak, sehingga dapat mengurangi perilaku temper tantrum.

Kata Kunci : pola asuh; temper tantrum; toddler

\section{PENDAHULUAN}

Pertumbuhan dan perkembangan anak tidak bisa dipisahkan terutama perkembangan motorik dan fisik yang sangat berhubungan dengan pertumbuhan psikis anak. Anak akan mengalami suatu periode yang dinamakan sebagai masa keemasan anak saat usia dini dimana saat itu anak akan sangat peka dan sensitif terhadap berbagai rangsangan dan pengaruh dari luar. Saat masa keemasan, anak akan mengalami tingkat perkembangan yang sangat drastis di mulai dari pekembangan berpikir, perkembangan emosi, perkembangan motorik, perkembangan fisik dan perkembangan sosial. Peningkatan perkembangan ini terjadi saat anak berusia 0-8 tahun, dan lonjakan perkembangan ini tidak akan terjadi lagi di periode selanjutnya (Anas, 2013).

Anak usia toddler adalah anak usia antara 1 sampai 3 tahun. Secara garis besar aspek pertumbuhan dan perkembangan anak terbagi menjadi 3 aspek yaitu, fisik, psikologik dan sosial, yang kesemuanya ini harus mendapatkan stimulasi yang seimbang. Masa Toddler terus meningkatkan kewaspadaan terhadap kemampuan anak untuk mengontrol dan senang dengan keberhasilan usaha keterampilan baru. Keberhasilan ini membuat mereka mengulangi usaha untuk mengontrol lingkungan anak. Ketidakberhasilan usaha pengontrolan dapat menimbulkan perilaku negatif seperti menghentak, membating barang, merengek, menangis, menjerit sekuat tenaga dan sebagainya yang dengan jelas menunjukkan ego dan selfpower dalam diri mereka mulai tumbuh dan terjadi temper tantrum (Watson dkk, 2010).

dari kemper tantrum adalah episode digambarkan dengan perilaku menangis, berteriak, namun tantrum juga dikatakan sebagai luapan frustrasi yang ekstrim, yang tampak seperti kehilangan kendali seperti dicirikan oleh perilaku gerakan tubuh yang kasar atau agresif seperti membuang barang, berguling di lantai, membenturkan kepala, dan menghentakkan kaki ke lantai. Pada anak yang lebih kecil (lebih muda) biasanya sampai muntah, pipis, atau bahkan nafas sesak karena terlalu banyak menangis dan berteriak. Akibat yang ditimbulkan dari temper tantrum ini cukup berbahaya, misalnya anak yang melampiaskan kekesalannya dengan cara bergulingguling dilantai yang keras dapat menyebabkan anak menjadi cedera. Anak yang melampiaskan amarahnya dapat menyakiti dirinya sendiri, menyakiti orang lain atau merusak benda yang ada disekitarnya. Jika benda-benda yang ada disekitar anak merupakan benda keras maka akan sangat berbahaya karena anak dapat tersakiti dan mengalami cedera 
akibat dari tindakan tantrumnya. Tantrum yang tidak diatasi dapat membahayakan fisik anak, selain itu anak tidak akan bisa mengendalikan emosinya atau anak akan kehilangan kontrol dan akan lebih agresif. Hal ini akan mengakibatkan anak tidak bisa menghadapi lingkungan luar, tidak bisa beradaptasi, tidak bisa mengatasi masalah (Dariyo, 2007).

\section{METODE PENELITIAN}

Metode penelitian yang digunakan adalah survey analitik (kuantitatif). Pendekatan yang digunakan dalam penelitian ini adalah cross sectional, dimana variabel sebab atau resiko dan akibat atau kasus yang terjadi pada obyek penelitian diukur atau dikumpulkan secara simultan (dalam waktu bersamaan) (Notoatmodjo, 2010). Variabel bebas pola asuh orang tua dan variabel terikat kejadian temper tantrum. Dalam penelitian ini menggunakan alat ukur kuisioner.

\section{HASIL PENELITIAN}

\section{Tabel. 1}

Distribusi Frekuensi Karakteristik Responden Hasil Penelitian di dukuh Pelem Kelurahan Baturetno Banguntapan Bantul

\begin{tabular}{clcc}
\hline No. & \multicolumn{1}{c}{ Karakteristik } & Frekuensi & Persentase \\
\hline 1. & Umur & 28 & \\
& a. 20-30 & 13 & $68,3 \%$ \\
& b. $>30$ & & $31,7 \%$ \\
2. & Pendidikan & & \\
& a. SD & - & - \\
& b. SMP & 2 & $4,9 \%$ \\
& c. SMA & 25 & $61,0 \%$ \\
d. Diploma/PT & 14 & $34,1 \%$ \\
3. Pekerjaan & & \\
& $\begin{array}{l}\text { a. IRT } \\
\text { b. PNS }\end{array}$ & 21 & $51,2 \%$ \\
& c. Wiraswasta & 7 & $7,3 \%$ \\
d. Swasta & 10 & $17,1 \%$ \\
4. Jenis kelamin & & $24,4 \%$ \\
& anak & 25 & $61,0 \%$ \\
\hline
\end{tabular}

a. Laki-laki $\quad 16 \quad 39,0 \%$

b. Perempuan

Tabel. 1 memperlihatkan bahwa karakteristik responden berdasarkan umur terbanyak pada kelompok umur 20-30 tahun dengan jumlah 28 responden $(68,3 \%)$. Hal ini menyatakan bahwa sebagian besar responden termasuk kelompok umur 20-30 tahun (dewasa awal). Umur merupakan salah satu faktor yang mempengaruhi perilaku kesehatan seseorang. Usia dewasa awal berdasarkan perkembangan psikososialnya merupakan masa dimana seorang individu mulai membina rumah tangga dan menjadi orang tua (Potter \& Perry, 2005). Hal ini didukung melalui penelitian Suyami (2009) bahwa usia orang tua mempengaruhi pola pengasuhan pada anak.

Berdasarkan pendidikan responden, terbanyak pada responden dengan pendidikan SMA yaitu 25 responden $(61,0 \%)$. Hal ini menyatakan bahwa sebagian besar responden berpendidikan SMA. Hasil penelitian Setyono (2009), menunjukkan tentang pengaruh tingkat pendidikan dan pengalaman mengasuh orang tua terhadap pola asuh anak. Orang tua dengan tingkat pendidikan dan pengalaman mengasuh yang cenderung rendah lebih memilih pola asuh yang lebih mengekang. Sedangkan orang tua dengan tingkat pendidikan dan pengalaman dalam mengasuh yang cenderung tinggi lebih memilih pola asuh seperti layang-layang atau tarik ulur. Jadi bisa disimpulkan bahwa, ada saat dimana orangtua mengasuh dengan memberikan kebebasan, dan ada saat dimana orangtua melarang sesuatu pada anaknya.

Berdasarkan pekerjaan responden, terbanyak pada responden dengan Ibu 
Rumah Tangga yaitu $21(51,2 \%)$. Hal ini menyatakan sebagian besar responden adalah Ibu Rumah Tangga atau tidak bekerja. Ibu yang tidak bekerja atau sebagai ibu rumah tangga mempunyai cukup banyak waktu untuk dapat memperhatikan dan mengurus anak agar anak dapat tumbuh dan berkembang secara optimal (Wahyuni, dkk. 2014).

Distribusi frekuensi kuisioner pola asuh orangtua memperlihatkan bahwa aspek memberikan cinta dan kasih sayang dengan persentase tertinggi pada pernyataan jarang yaitu saya enggan mendengarkan cerita anak tentang temantemannya $(68,2 \%)$, berarti ibu mendengarkan cerita anak tentang temantemannya. Pernyataan jika anak murung dan mulai menangis, saya akan sering memeluknya $(63,4 \%)$, ketika anak belajar, saya akan membaca buku di dekatnya $(60,9 \%)$, dan persentase terendah pada pernyataan saya sering cuek saat anak menangis $(53,6 \%)$.

Indikator memuji anak atau mengkritik tingkah laku anak memperlihatkan bahwa dengan persentase tertinggi pada pernyataan saya akan selalu memberikan pengarahan ketika anak melakukan hal-hal yang baik $(53,7 \%)$, saya mengajari anak saya makan sendiri bersama teman-temannya saat bermain di rumah $(41,4 \%)$, saat anak melakukan kesalahan, saya jarang tegas mengatakan itu salah dan hal buruk $(39,0 \%)$, dan persentase terendah pada pernyataan saya sering meminta anak saya agar bisa makan sendiri seperti temannya (46,3\%), dan saya jarang akan memberikan pujian ketika anak melakukan hal-hal yang baik $(39,0 \%)$.

Indikator menciptakan aturan yang wajar memperlihatkan persentase tertinggi pada pernyataan saya akan sering mengabulkan permintaan anak jika itu baik untuknya $(53,6 \%)$, pernyataan saya tidak pernah membiarkan anak saya masuk saat saya berganti pakaian $(48,7 \%)$, pernyataan saya jarang memberi hukuman kepada anak ketika ia merusak mainannya (46,3\%), dan persentase terendah terdapat pada pernyataan semua kegiatan seharihari anak sering sudah ada jadwalnya $(43,9 \%)$.

Indikator menjadi model yang baik untuk anak dengan persentase tertinggi pada pernyataan saya tidak pernah akan memukul pantat anak saat ia tidak segera melakukan perintah saya $(68,2 \%)$, pernyataan acara yang saya tunggu sedang tayang, saya tidak pernah tetap menonton TV saat adzan maghrib berkumandang (46,3\%), dan persentase jawaban terendah pada pernyataan saya jarang akan menegur dengan lembut ketika anak mengganggu temannya $(56,09 \%)$.

Indikator konsisten dengan persentase tertinggi pada pernyataan saya dan suami sering sepakat mengadakan syukuran ulang tahun anak $(53,6 \%)$, dan persentase terendah terdapat pada pernyataan saya tidak pernah akan membelikan jajan saat anak menangis, meskipun itu melebihi jatah jajan ia sehari $(51,2 \%)$.

Indikator memberikan tanggung jawab dengan persentase tertinggi pada pernyataan saya selalu membiasakan anak untuk makan di waktu yang tepat $(51,2 \%)$ dan pernyataan saya tidak pernah membiarkan saja ketika anak lama bermain air $(51,2 \%)$, pernyataan saya jarang berencana mengikutkan anak ke beberapa kegiatan non formal (les) dan meminta pendapatnya (46,3\%), pernyataan saat anak berusaha mengambil mainan yang berada di rak tinggi dengan memanjat kursi, saya selalu dan sering 
siaga mengamatinya. Sedangkan persentase terendah terdapat dalam pernyataan saya berencana mengikutkan anak ke beberapa kegiatan non formal (les) dan jarang meminta pendapatnya $(46,3 \%)$.

Distribusi jawaban kuisioner kejadian temper tantrum pada anak usia toddler memperlihatkan bahwa pada aspek menyerang yang bersifat fisik pada indikator menghentakkan kaki jarang pada pernyataan walau sedang marah, anak saya tetap diam $(65,8 \%)$, hal itu artinya walau sedang marah, anak jarang tetap diam.

Kejadian temper tantrum pada indikator memukul terlihat dalam pernyataan anak saya jarang diam saja ketika mainannya direbut oleh temannya $(46,3 \%)$.

Indikator membenturkan kepala, peneliti hanya mencantumkan satu pernyataan yaitu anak saya membenturkan kepalanya ke dinding ketika marah, pada distribusi hasil jawaban kuisioner responden didapatkan jawaban tertinggi adalah tidak pernah $(95,1 \%)$.

Pada indikator menendang kejadian temper tantrum terlihat pada pernyataan yaitu ketika sedang marah, anak saya tidak pernah akan mengurung diri di kamar $(60,9 \%)$.

Indikator membanting pintu kejadian temper tantrum tidak terlihat, hal ini terlihat dari persentase jawaban tertinggi terdapat pada pernyataan positif, yaitu pada pernyataan anak saya tidak pernah membanting pintu ketika keinginannya ditolak $(70,7 \%)$, pernyataan ketika dilarang menonton kartun kesukannya, anak saya tidak pernah langsung masuk kamar dengan membanting pintu kamarnya $(68,2 \%)$, pernyataan ketika keinginannya belum terpenuhi, anak saya sering bisa menerima $(41,4 \%)$.

Hal sama juga terlihat pada indikator melemparkan dan merusak barang kejadian temper tantrum tidak terlihat. Hal ini terbukti dari pernyataan anak saya tidak pernah melempar mainannya ketika dia merasa bosan $(53,6 \%)$, dan pernyataan saat jengkel, anak saya tidak pernah melemparkan barang-barang yang ada di dekatnya $(51,2 \%)$.

Aspek menyerang secara verbal yaitu indikator menangis dengan keras kejadian temper tatrum terlihat pada pernyataan anak saya sering menangis dengan keras ketika ia dilarang bermain (46,3\%), pernyataan dimanapun tempatnya, anak saya menangis dengan keras ketika sedang marah $(43,9 \%)$, dan persentase terendah pada pernyataan saya jarang mengajak anak saya pergi, karena ia anak yang patuh $(43,9 \%)$.

Indikator merengek kejadian temper tantrum terlihat pada pernyataan anak saya sering meminta pulang jika ia bosan saat berada di tempat baru $(68,2 \%)$, pernyataan ketika menginginkan jajan, anak jarang meminta tanpa merengek kepada saya $(51,2 \%)$, pernyataan bila menginginkan sesuatu, anak saya jarang akan merengek hingga keinginannya terpenuhi $(43,9 \%)$.

Indikator berteriak dan menjerit kejadian temper tantrum terlihat pada pernyataan ketika sedang berada di keramaian, anak saya jarang bisa menjaga emosinya $(58,5 \%)$

Indikator mengumpat dan memaki kejadian temper tantrum terlihat jarang terjadi, hal ini terdapat pada pernyataan ketika berbelanja anak berteriak/menjerit jika saya menolak membelikan mainan. Hal itu artinya beberapa anak masih ada 
yang berteriak/menjerit saat ibu menolak membelikan mainan.

Sebelum dilakukan uji statistik, dilakukan uji normalitas menggunakan Shapiro Wilks karena responden $\leq 50$.

Tabel. 2

\begin{tabular}{llll}
\multicolumn{3}{c}{$\begin{array}{c}\text { Hasil uji normalitas data dengan uji } \\
\text { Shapiro-Wilk }\end{array}$} & \\
\cline { 1 - 2 } & Shapiro- & \\
Wilk & & \\
\hline Pola asuh & Statistic & Df & Sig. \\
Kejadian temper & .961 & 41 & .169 \\
tantrum & .983 & 41 & .786 \\
\cline { 1 - 2 }
\end{tabular}

Tabel. 2 memperlihatkan bahwa untuk data pola asuh orangtua didapatkan nilai signifikasi (p) sebesar 0,169 lebih besar dari 0,05 sedangkan untuk variabel kejadian temper tantrum didapatkan nilai signifikansi (p) sebesar 0.786 lebih besar dari 0,05. Dengan demikian dapat disimpulkan bahwa data pola asuh orangtua dan kejadian temper tantrum dinyatakan berdistribusi normal.

Tabel. 3

Tabel Pola Asuh Orang Tua Dengan Kejadian Temper Tantrum Pada Anak Usia Toddler Di Dukuh Pelem Kelurahan Baturetno Banguntapan Bantul.

\begin{tabular}{lc}
\hline & $\begin{array}{c}\text { Pola asuh dengan temper } \\
\text { tantrum }\end{array}$ \\
\hline Pearson & .344 \\
Correlation & .027 \\
Sig. (2-tailed) & 41 \\
$\mathrm{~N}$ & 3 \\
\hline
\end{tabular}

Berdasarkan table 3 menunjukkan hasil uji statistik korelasi Product Moment didapatkan bahwa nilai person korelasi antara pola asuh orangtua dengan kejadian temper tantrum pada anak usia toddler di dukuh Pelem Kelurahan Baturetno Banguntapan Bantul sebesar 0,344 yang menunjukkan tingkat hubungan rendah dan nilai signifikan (p) adalah 0,027. Karena signifikan perhitungan yang diperoleh $\mathrm{p}$ value $=0,027(\mathrm{p}<0,05)$, maka Ho ditolak dan Ha yang menyatakan terdapat hubungan antara pola asuh orangtua dengan kejadian temper tantrum pada anak usia toddler di dukuh Pelem Kelurahan Baturetno Banguntapan Bantul diterima. Dengan demikian dapat disimpulkan bahwa terdapat hubungan antara pola asuh orangtua dengan kejadian temper tantrum pada anak usia toddler di dukuh Pelem Kelurahan Baturetno Banguntapan Bantul tahun 2015.

\section{PEMBAHASAN}

Berdasarkan hasil penelitian yang dilakukan peneliti menunjukkan bahwa responden memiliki pola asuh sudah baik pada indikator pernyataan jika anak murung dan mulai menangis, saya sering akan memeluknya, pernyataan ketika anak belajar, saya sering akan membaca buku didekatnya, pernyataan saya jarang enggan mendengarkan cerita anak tentang teman-temanya, dan pola asuh yang cenderung kurang baik pada aspek memberikan cinta dan kasih sayang. Hal ini dibuktikan pada indikator pernyataan saya sering cuek saat anak menangis. Dampaknya apabila ibu tetap cuek, semakin membuat anak merasa takut. Padahal dengan banyak memberikan kesempatan bercerita pada anak, melihat apa yang menyebabkan menangis, hal ini dapat meminilmalisir emosi anak, dan dapat mengetahui apa penyebab kemarahannya.

Saat anak mengalami ledakan emosi, jika ibu tidak bisa menahan emosi atau ikut marah, kemungkinan akan meninggalkan anaknya sendirian. Jangan lakukan itu! Anak akan merasa lebih 
tenang jika ibu tetap berada didekatnya. Jika memungkinkan gendonglah atau peluklah, sehingga anak lebih cepat menenangkan diri (Hasan, 2011).

Hasil penelitian ini pada aspek memuji atau mengkritik tingkah laku anak memperlihatkan gambaran pola asuh orangtua yang sudah baik pada pernyataan saya selalu memberikan pengarahan ketika anak melakukan hal-hal yang baik, pernyataan saya sering mengajari anak melakukan makan sendiri bersama temantemannya saat bermain di rumah, pernyataan saat anak melakukan kesalahan, saya jarang tegas mengatakan itu salah dan hal yang buruk.

Hal berbeda ditemukan yaitu pola asuh yang cenderung negatif atau kurang baik. Hal ini dibuktikan pada indikator pernyataan saya jarang memberikan pujian ketika anak melakukan hal-hal baik, dan pernyataan saya sering meminta anak saya agar bisa makan sendiri seperti teman-temannya, hal ini berarti ibu menginginkan anak sama seperti temantemannya yang dapat makan sendiri atau dengan kata lain membandingkan anak dengan temannya. Dampaknya apabila orangtua jarang memuji anak menjadi tidak bisa mandiri, dan menghargai orang lain, sedangkan apabila membandingkan anak dengan yang lain juga dapat membuat satu anak mengembangkan persaingan dengan saudaranya atau temannya.

Berdasarkan penelitian ini menunjukkan aspek menciptakan aturan yang wajar sudah dilakukan ibu dengan baik. Hal ini dibuktikan dari pernyataan saya akan sering mengabulkan permintaan anak jika itu baik untuknya, semua kegiatan sehari-hari anak sering sudah ada jadwalnya, saya jarang memberi hukuman kepada anak ketika ia merusak mainannya, dan saya tidak pernah membiarkan anak saya masuk saat saya berganti pakaian.

Berdasarkan penelitian ini dalam aspek menjadi model yang baik untuk anak masih belum dilakukan oleh ibu. Hal ini dibuktikan pada indikator saya jarang menegur dengan lembut ketika anak mengganggu temannya, hal itu berarti ibu masih menggunakan cara kurang lembut dalam menegur anak. Dampaknya saat melihat orangtua mudah meluapkan kemarahan, ini akan menjadikan anak merasa takut dan cenderung diam.

Sebaiknya saat anak melakukan kesalahan atau sedang mengalami ledakan emosi, baik dengan teriakan maupun tindakan fisik lainnya, dia tidak akan bisa menerima alasan atau bujukan. Apa pun yang dilakukan oleh ibunya, anak akan tetap merespon negatif (Hasan, 2011).

Indikator memberikan tanggung jawab juga masih kurang, hal ini dibuktikan dengan pernyataan saya berencana mengikutkan anak ke beberapa kegiatan non formal (les) dan jarang meminta pendapatnya. Hal ini berarti ibu jarang meminta pendapat anak, dampaknya anak menjadi kurang percaya diri dan sulit bertanggungjawab.

Temper tantrum seringkali terjadi pada anak-anak yang terlalu sering dicemaskan oleh orang tuanya, serta sering muncul pula pada anakanak dengan orang tua yang bersikap terlalu melindungi, tidak konsisten, tidak memberikan kesempatan pada anak untuk bercerita. Lingkungan sosial rumah mempengaruhi intensitas dan kuatnya amarah anak. Ledakan amarah lebih banyak timbul di rumah bila ada banyak tamu atau ada lebih dari dua orang dewasa (Hasan, 2011). 
Berdasarkan penelitian yang dilakukan di Dukuh Pelem, kejadian temper tantrum yang sering terjadi adalah indikator anak merengek, menangis, berteriak dan menjerit. Hal ini terlihat pada pernyataan sering yaitu anak saya meminta pulang jika ia bosan saat berada di tempat baru $(68,2 \%)$ dan sering pada pernyataan anak saya menangis dengan keras ketika ia dilarang bermain $(46,3 \%)$, sedangkan kejadian temper tantrum jarang terlihat pada aspek menghentakkan kaki dengan indikator pernyataan walau sedang marah, anak jarang tetap diam, pada aspek memukul dengan indikator anak saya jarang diam saja ketika mainannya direbut oleh temannya. Pada aspek merengek pada indikator ketika menginginkan jajan, anak jarang meminta tanpa merengek kepada saya. Pada aspek berteriak dan menjerit pada indikator ketika sedang berada dikeramaian, anak saya jarang bisa menjaga emosinya.

Hal ini sesuai dengan kategori yang dijabarkan menurut Potegal (2011) yaitu, kemarahan sedang ini bisa disebut juga dengan kesedihan yaitu, menangis, merengek, rewel. Ia menegaskan bahwa apabila anak sudah mulai menjerit maka sudah masuk dalam kemarahan intensitas tinggi.

Penelitian yang telah dilakukan memberikan hasil bahwa ada hubungan secara statistik antara pola asuh orangtua dengan kejadian temper tantrum karena memiliki taraf signifikansi $\mathrm{p}=0,027(\mathrm{p}<$ $0,05)$, sehingga dapat ditarik kesimpulan bahwa Ho ditolak dan Ha diterima.

Hasil penelitian ini didukung oleh penelitian Suyami (2009) yang menyatakan ada hubungan antara pola asuh orang tua dengan perkembangan anak usia 1-3 tahun, dengan hasil uji statistik $\mathrm{r}$ hitung $0,4378>\mathrm{r}$ tabel 0,256 , dengan taraf signifikansi 0,00 (p: < 0, 01).

Hasil penelitian Mediansari (2014) bahwa semakin tinggi kecerdasan emosional orang tua, semakin rendah perilaku temper tantrum muncul pada anak, dengan hasil uji statistik korelasi sedang $(\mathrm{r}=-0.502)$.

Jenis disiplin dan metode latihan anak juga mempengaruhi frekuensi dan intensitas ledakan amarah anak. Anak yang terlalu dimanjakan dan selalu mendapatkan apa yang diinginkan bisa temper tantrum ketika permintaannya ditolak. Bagi anak yang terlalu dilindungi dan didominasi oleh orang tuanya, sekali waktu anak bisa bereaksi menentang dominasi orang tua dengan perilaku temper tantrum. Orang tua yang mengasuh secara tidak konsisten juga bisa menyebabkan anak tantrum. Misalnya, orang tua yang tidak mempunyai pola yang jelas kapan ingin melarang atau kapan ingin mengizinkan anak berbuat sesuatu, dan orang tua yang seringkali mengancam untuk menghukum tapi tidak pernah menghukum. Anak akan dibingungkan oleh orang tua dan menjadi tantrum ketika orang tua benar-benar menghukum. Ayah dan ibu yang tidak sependapat satu sama lain, yaitu yang satu memperbolehkan anak dan yang lain melarang anak. Anak bisa menjadi temper tantrum agar mendapatkan keinginan dan persetujuan dari kedua orang tua (Baihaqi, 2013).

Pengasuhan dengan kasih sayang, diskusi dan penalaran untuk membantu anak mengerti mengapa perilaku tertentu diharapkan akan menghasilkan anak yang memiliki penyesuaian pribadi dan sosial yang baik, kemandirian dalam berpikir, inisiatif dalam tindakan dan konsep diri yang sehat, positif, penuh rasa percaya 
diri, terbuka dan spontan, sehingga dapat mengurangi perilaku temper tantrum. Pengasuhan yang dimana orang tua menerapkan aturan-aturan dan batasanbatasan yang mutlak harus dituruti oleh anak, serta menggunakan hukuman fisik untuk menghukum anak, akan menghasilkan anak yang tidak bahagia, ketakutan, minder, memiliki kemampuan komunikasi yang lemah, dan agresif, sehingga temper tantrum akan sering terjadi (Hasan, 2011; Edy,2012).

Pengasuhan yang dimana membiarkan anak-anak mencari dan menemukan sendiri tata cara yang memberi batasan-batasan dari tingkah lakunya, orangtua tidak banyak terlibat dalam kehidupan anak serta tidak banyak menuntut atau mengontrol anak, sehingga anak tidak belajar untuk menghormati orang lain, selalu ingin mendominasi, tidak menuruti aturan, egosentris, mengalami kesulitan dalam mengendalikan perilaku serta kesulitan dalam menghadapi larangan larangan yang ada di lingkungan sosial, sehingga ketika keinginannya tidak terpenuhi ia akan temper tantrum (Baihaqi, 2013; Suwaid, 2009).

\section{KESIMPULAN DAN SARAN}

Terdapat hubungan antar pola asuh orangtua dengan kejadian temper tantrum pada anak usia toddler di Dukuh Pelem, Kelurahana Baturetno, Banguntapan, Bantul tahun 2015 dengan nilai signifikansi Pearson Product Moment sebesar 0,027 ( $\mathrm{p}<0,05)$. Orangtua dapat memberikan pengasuhan dengan kasih sayang, menciptakan aturan yang wajar yang berlaku dalam keluarga, konsisten, memberikan tanggung jawab, akan menghasilkan anak yang memiliki penyesuaian pribadi dan sosial yang baik, kemandirian dalam berpikir, inisiatif dalam tindakan dan konsep diri yang sehat, positif, penuh rasa percaya diri, terbuka, sehingga dapat mengurangi perilaku temper tantrum. Pada aspek memberikan cinta dan kasih saayang dengan memeluk saat anak menangis. Pada aspek memuji dan mengkritik tingkah laku anak, dengan membiasakan memberikan pujian jika anak melakukan hal baik, tidak membandingkan dengan teman atau saudaranya. Pada aspek menjadi model yang baik, menegur dengan lembut saat anak melakukan kesalahan, tidak menjudge. Pada aspek memberikan tanggungjawab dengan mengikutkan anak dalam mengambil keputusan, atau minta pendapat anak.

\section{DAFTAR RUJUKAN}

Anas, Muhammad. (2013). Psykologi Menuju Aplikasi Pendidikan. Jakarta : Pustaka Eduction

Dariyo, Agoes. (2007). Psikologi Perkembangan Anak Tiga Tahun Pertama. Bandung : Refika Aditama.

Edy. (2012). Ayah Edy menjawab : 100 persoalan sehari-hari orangtua yang tidak ada jawabannya di kamus mana pun. Jakarta : Noura Books

Hasan, Maimunah. (2011). Pendidikan Anak Usia Dini. Yogyakarta: Diva Press.

Hayes, Eileen. (2003). Tantrum. Jakarta: Erlangga

Mediansari. (2014). Hubungan Kecerdasan Emosional Orang Tua dengan Perilaku Temper Tantrum Anak Usia Toddler. Program Studi Diploma IV Bidan Pendidik Fakultas Kedokteran Universitas Sebelas Maret Surakarta. 
Mireault, Gina., Trahan, Jessica. (2007). Tantrums and Anxiety in Early Childhood. Journal ECRP, 9 (2) Tahun 2007.

Notoatmodjo, S (2010). Metodologi penelitian kesehatan. Edisi Revisi. Jakarta : Rineka Cipta.

Potegal, M., Whitney, P., \& Green, J. (2011). Screaming, Yelling, Whining and Crying: Categorical and intensity differences in Vocal Expressions of Anger and Sadness in Children's Tantrums. Journal of Developmental and Behavioral Pediatrics Emotion. 2011 Oct; 11 (5): 1124-1133.

Potter \& Perry. (2005). Buku Ajar Fundamental Keperawatan : Konsep, Proses \& Praktek. Edisi 4. Vol 1. Jakarta : EGC Psikologizone. 2012

Suyami. (2009). Pola Asuh Orang Tua dengan Tingkat Perkembangan Sosial Anak Usia 1 - 3 Tahun Di Desa Buntalan Iclaern. Jurnal Keperawatan STIKES Muhammadiyah Klaten Tahun 2009.
Tandry, Novita. (2010). Bad Behaviour, Tantrums and Tempers. Jakarta : Gramedia

Tiffany, Cooke \& Gray, Lawrence. (2012). Temper Tantrums and Management. Pediatrics University of Chicago.

Wahyuni, Sulistyani, Ratnawati. (2014). Dampak Program Bina Keluarga Balita (BKB) Terhadap Tumbuh Kembang Anak Balita 6-24 Bulan. e-Jurnal Pustaka Kesehatan, 2 (1) Januari 2014.

Wakschlag, Lauren S., Choi, Seung W., Carter, Alice S. (2012). Defining the developmental parameters of temper loss in early childhood: implication for developmental psychopathology. The Journal of Child Psychology and Psychiatry, 53 (11) November 2012.

Watson, S., Watson, T., \& Gebhardt, S. (2010). Temper Tantrums: Guiedelines for Parents and Teachers. National Assosiation of School Psychologists, Miami University : Oxford O 